International Journal of Medical Arts 2020; 2 [3]: 508-518.

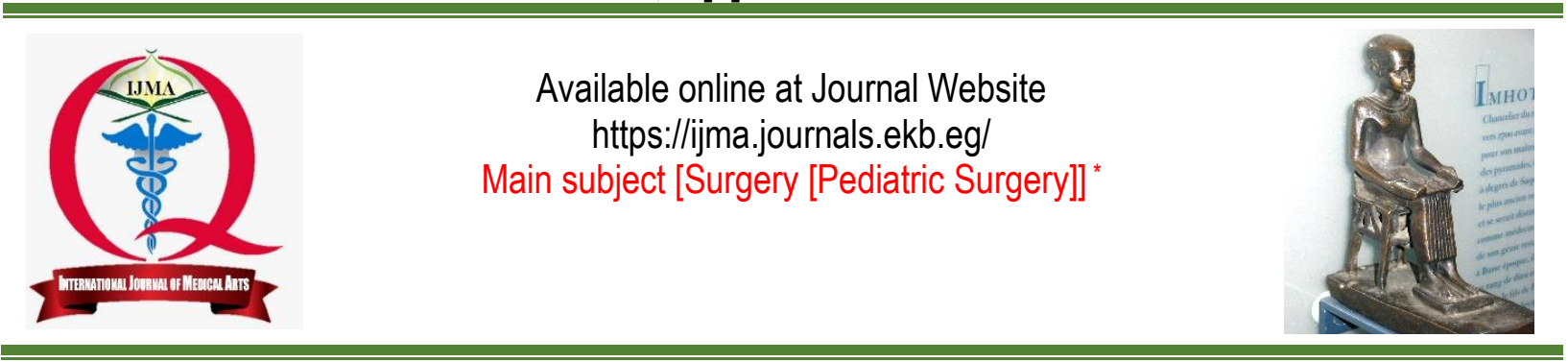

Original article

\title{
Comparative Study between Mathieu Repair and Snodgrass Repair in Distal Hypospadias
}

\author{
Ahmad Alaa-eldeen Hassouna ${ }^{[a]}$; Abdo Abdo Arnous ${ }^{[b]}$; Esam Ali Taman ${ }^{[c]}$; Ibrahim Mahmoud \\ Elsayaad $[\mathbf{b}]$
}

Department of General Surgery, Damietta General Hospital, Ministry of Health, Egypt ${ }^{[a]}$.

Department of Pediatric Surgery, Damietta Faculty of Medicine, Al-Azhar University, Egypt ${ }^{[b]}$

Department of Plastic Surgery, Damietta Faculty of Medicine, Al-Azhar University, Egypt[c]

Corresponding author

Ahmad Alaa-eldeen Hassouna

Email: drahmadalaa6@gmail.com

Received at: March 16, 2020; Revised at: June 01, 2020; Accepted at: June 02, 2020; Available online at: June 02, 2020

DOI: 10.21608/ijma.2020.26016.1109

\section{ABSTRACT}

Background: Hypospadias is a congenital condition characterized by tissue hypoplasia of the ventral aspect of the penis, with incidence of one in 300 males [0.3\%]. There is an increase incidence in those with first-degree relatives having hypospadias to about 13 times more than those without family history.

Aim of the work: To compare between the meatal-based flap "Mathieu" technique and tubularized incised plate [TIP] "Snodgrass urethroplasty in treatment of distal hypospadias.

Patients and Methods: This study was carried out at the Department of Surgery, Al-Azhar university hospital [Damietta], Egypt., The study consists of forty male children, suffering from distal penile hypospadias. Patients were blindly assigned into two groups;20 patients underwent Mathieu technique and another 20 patients underwent "Snodgrass urethroplasty".

Results: Both groups were comparable regarding patient age, consanguinity, maternal drug intake, urethral plate characteristics and duration of hospital study. However, Snodgrass urethroplasty is associated with significant increase of operative time [ $80.0 \pm 16.1$ vs $60.0 \pm 9.6$ minutes], significant lower complication rate [10\% vs $30.0 \%$ ], significantly good cosmetic appearance of the penis [100\% excellent versus $40 \%$ excellent, $40 \%$ good, and $20 \%$ torsion of the shaft] and $100 \%$ slit like and vertically oriented meatus.

Conclusion: Snodgrass and modified Mathieu repair are safe, and the choice of one of the techniques will depend on the surgeon's decision. Its procedure had its own advantages and disadvantages and final decision should be attributed to surgeon preferences.

Keywords: Snodgrass; Urethroplasty; Mathieu; Hypospadias; Congenital.

This is an open access article under the Creative Commons license [CC BY] [https://creativecommons.org/licenses/by/2.0/]

Please cite this article as: Hassouna AA, Arnous AA, Taman EA, Elsayaad IM. Comparative Study between Mathieu Repair and Snodgrass Repair in Distal Hypospadias. IJMA 2020; 2[3]: 508-518.

${ }^{*}$ Main subject and any subcategories have been classified according to research topic. 


\section{INTRODUCTION}

Throughout Greek culture, there was high appreciation for the goddess Hermaphrodite, who was half man and half woman. Many statues reflect hypospadiac genitalia, perhaps indicative of admiration for this condition. It is, therefore, understandable why it was not until the first and second centuries A.D. that the Alexandrian surgeons Heliodorus and Antyllus attempted to correct this anomaly by amputation of the distal curved portion [1]

Sexually, the dystopia of the meatus may cause infertility. Henry II of France was known to have hypospadias, as recorded by his physician Fernal. Henry's marriage with Catherine de Medici was infertile until Fernal "advised his patient that in such cases coitus more ferarum [Vaginal penetration from rear] permitted him to overcome the difficulty." Henry II went on to sire three kings of France, along with seven other children. [2] From congenital anomalies, hypospadias is the commonest, affecting 1 from each 250 newborns, or approximately 1 in 125 live male births. [3] Hypospadias is defined as an arrest in standard growth of the penile urethra, foreskin, and penile ventral aspect [4] This leads to different abnormalities; the urethral opening can be presented anywhere along the penis ventral shaft, within the scrotum, or even in the perineum. Hypospadias is also associated with a ventral curvature of the penis, or chordee. If uncorrected, in severe cases, patients were urged to sit down for voiding and tend to avoid intimate relationships due to fears of abnormal sexual acts. Babies with severe condition and "ambiguous genitalia" in the neonatal period, could have difficulty in accurate sex determination. Hypospadias is classified by the location of the urethral meatus. Mild [distal] hypospadias may be glandular [meatus on the ventral surface of the glans penis], coronal [meatus in the balanopenile furrow], or distal [in the distal third of the penile shaft]. Moderate hypospadias is along the middle third of the penile shaft. Severe [posterior] hypospadias extends through the proximal third of the penile shaft to the perineum and may be described as posterior penile [at the base of the shaft], penoscrotal [at the base of the shaft in front of the scrotum], scrotal [on the scrotum or between the genital swellings], or perineal [behind the scrotum or behind the genital swellings]. [5]

Classifying hypospadias is not necessarily useful in determining surgical approach, and these classifications do not take into account the associated penile curvature. A patient with severe curvature and an anterior urethral meatus may require more extensive surgery to correct both

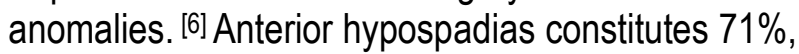
middle $16 \%$, and posterior $13 \%$ [7]. Between congenital anomalies, hypospadias is unique as it has different surgical techniques for the treatment of a single condition [8]. The object of therapy is to reconstruct a straight penis with a meatus as close as possible to the normal site [ventrum of the terminal aspect of the glans] to allow a forwarddirected urine stream and normal coitus. There are five basic phases for a successful hypospadias outcome: [1] urethroplasty [straightening], [2] urethroplasty, [3] meatoplasty and glanuloplasty, [4] scrotoplasty, and [5] skin cover. These elements can be applied successively or in different combinations to attain surgical success. [9]

The management of distal hypospadias is affected by the cultural predilection of the child's family. Many children who had distal hypospadias, actually do not have any defects in their functional, lack significant penile curvature, and will be able to void with a straight stream in the upright position. Therefore, the aim of restoring the meatus to its normal position within the glans is principally cosmetic. The main outcome requires to be as close to standard perfect situation as possible. [10] The present standard intervention is outpatient surgery. The applied technique depends on the anatomy [anomaly] of the hypospadiac penis. The commonest procedures performed presently are the meatal advancement with glansplasty incorporated [MAGPI], the glans approximation procedure [GAP], primary tubularization, the Mathieu or flip-flap, and the Duplay or primary tubularization with the incision of the urethral plate [Snodgrass modification] when the plate is too small for primary closure.[11] In 1928, "Mathieu" described a surgical technique to repair distal penile or anterior hypospadias in a single operation. The results of this technique were first reported in 1932 [12]. Since then, and due to the successful results achieved, the maneuver has been popularized by Kim \& Hendren [13], Gonzales et al. [14] Tabularized Incised Plate "Snodgrass" urethroplasty [TIP] first described in 1994 by Snodgrass [15].Following that study, clinical experiences were reported from many organizations and has shown 
that, this maneuver is applicable to fundamentally all patients with distal hypospadias, without concern for the specific meatal configurations [16].

\section{AIM OF THE WORK}

The aim of the work is to compare between the meatal-based flap "Mathieu" technique and tubularized incised plate [TIP] "Snodgrass urethroplasty in treatment of distal hypospadias. Regarding operative time, postoperative follow up, success rates, functional and cosmetic results, incidence of complications and advantages of each technique.

\section{PATIENTS AND METHODS}

This study was a comparative prospective randomized cohort study, in which all patients with the distal penile hypospadias, were selected till the sample size was fulfilled. It was carried out at The Department of Surgery, Al-Azhar university hospital in new Damietta, Egypt. The study extended from January 2018 to December 2019.

Exclusion criteria: Patients who refuse to participate in the study, and those with other types of hypospadias [midshaft \& proximal], and recurrent type of hypospadias were excluded from the study.

The study consists of forty male children with age group ranging from 1 year to 15 years, suffering from distal penile hypospadias. Preoperatively, all eligible patients were subjected to clinical assessment [history and clinical examination [general and urogenital examination]. Local examination was done for skin quality especially ventral type, external urethral meatus and presence of chordee, size of penis, scrotum and testis. In addition, all underwent laboratory assessment [complete blood count, coagulation profile, liver and kidney functions, urine analysis with culture and sensitivity]. Finally, radiological assessment included formal Pelviabdominal ultrasound for urogenital disorders.

Operative procedure [Figures 1-7 for Mathieu technique and Figures 8- for Snodgrass technique].

Patients were blindly assigned into two random groups: Group A: 20 patients underwent Mathieu technique. In this group, pre-marking, we separate the glans and the prepuce and clean the smegma or any debris. Commencing the procedure by applying a tourniquet to the penile base with local anesthetic injection [Xylocaine plus adrenaline] for local hemostasis. The distance between hypospadiac meatus and tip of penis is measured. A distance from meatus was measured on proximal penile shaft and kept 1.5- 2 times longer than the length measured from native meatus to the tip of glans. A width of 7.5$8 \mathrm{~mm}$ is measured from the proximal flap. The width is tapered to $5.5-6 \mathrm{~mm}$ at the glanular groove. A 5/0 vicryl suture with rounded needle is inserted to the dorsal surface of the glans. After checking the urethra, a u-shaped incision is made along the marks, then creating the flap for the neo urethra with meticulous sharp dissection, gentle handling of tissues and minimal use of electro-cautery. Following adequate flap preparation, we incise at the glans for flap with making sure that the two wings of the glans can be approximated. Insertion of a Nelaton catheter as a stent and creating the neo urethra through flipping the proximal end of the flap distally by $6 / 0$ vicryl continuously. Check the leakage by saline injection, then reinforcement with a second layer. A circular incision is made as a prepuce to start degloving, after that covering the neo urethra by closing the two wings of the glans with $5 / 0$ vicryl sutures. Fix the neo urethra to the glanular wings with $6 / 0$ vicryl suture. Making a dorsal slit at the prepuce till the level of corona, then rotate the divided parts to cover the ventral raw area as Byars flap. Finally, close the wound in a z-zag fashion to cover the ventral area with fixation of the stent to the glans.

In group B, 20 patients underwent Snodgrass technique.

After assessment of the urethra, foreskin and ventral aspect, we commence the procedure by applying tourniquet around the penile base with gradual release every 20-30 minutes to prevent ischemia and achieve hemostasis. A 4/0 vicryl traction suture is placed in the glans just distal to the expected dorsal lip of the neo meatus. A circumscribing U-shape skin incision is made 1-2 $\mathrm{mm}$ proximal to the meatus followed by degloving of shaft skin till penoscrotal junction by sharp dissection with a knife incision and then fine scissors.

Dissection is started ventrally, then dorsally as it is safer plane for dissection. Complete the degloving by lateral dissection. Y-shaped spongiosum is seen going on either side to the glans wings. 


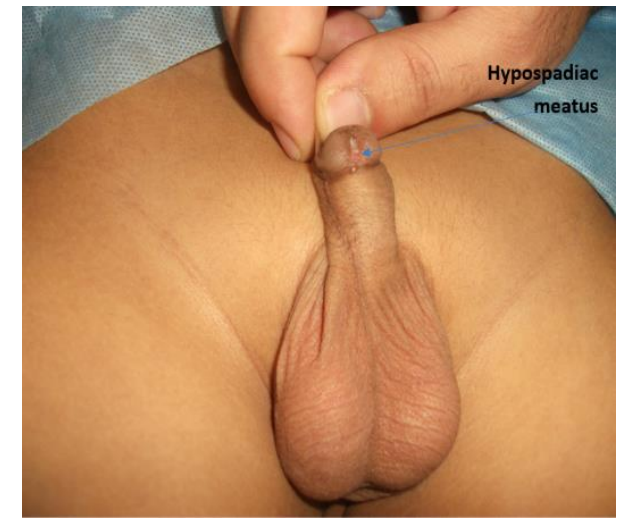

Figure [1]: Distal hypospadias case

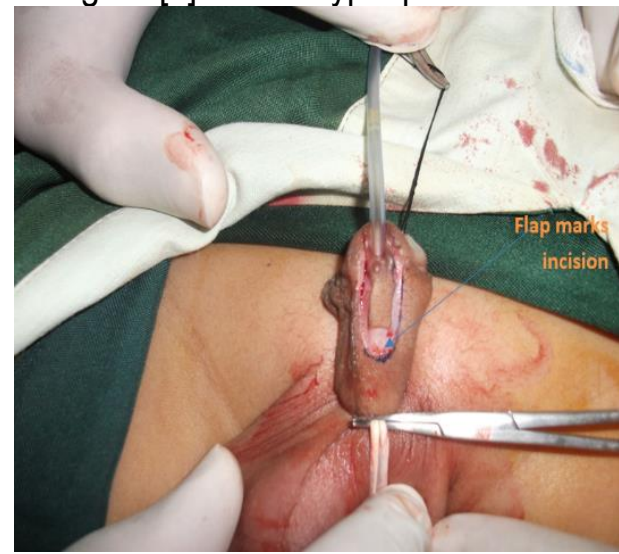

Figure [3]: Mathieu flap incision.

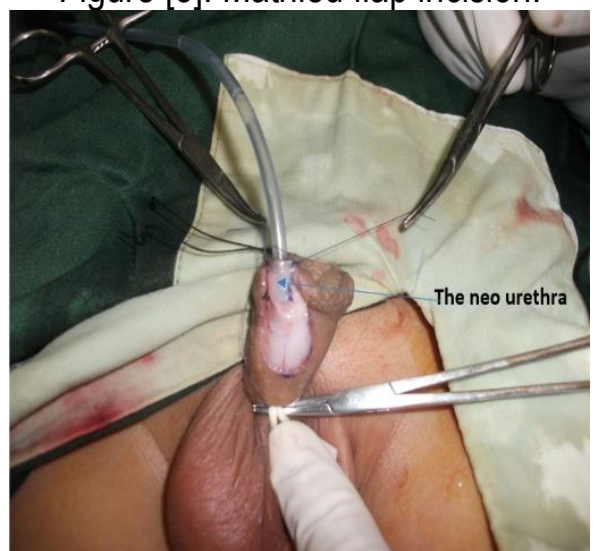

Figure [5]: Mathieu urethroplasty

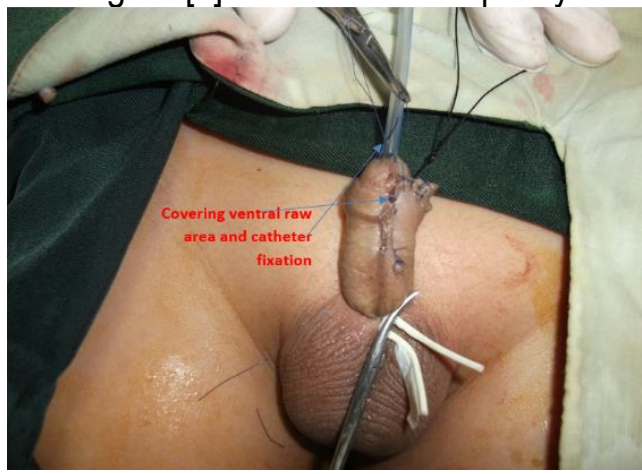

Figure [7]: Covering ventral raw area.

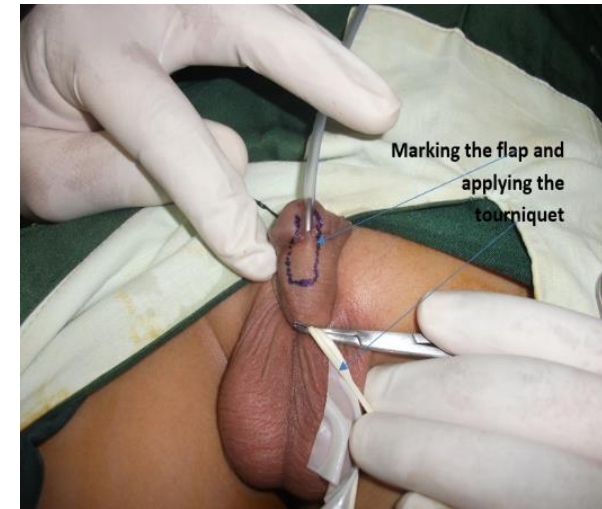

Figure [2]: Marking Mathieu flap

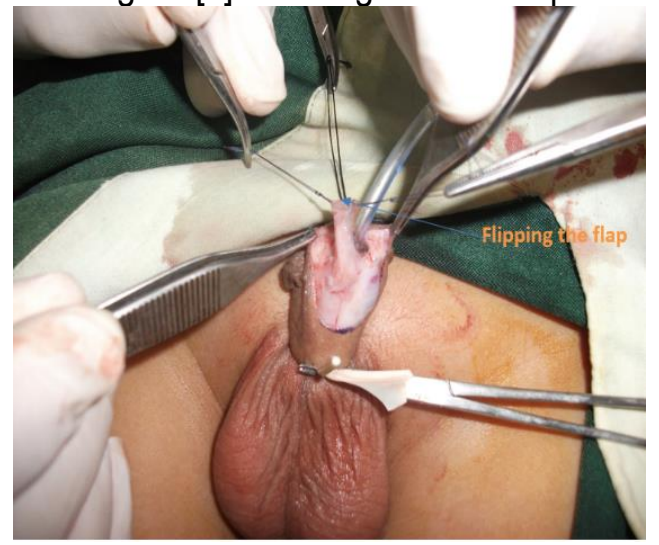

Figure [4]: Flipping of Mathieu flap.

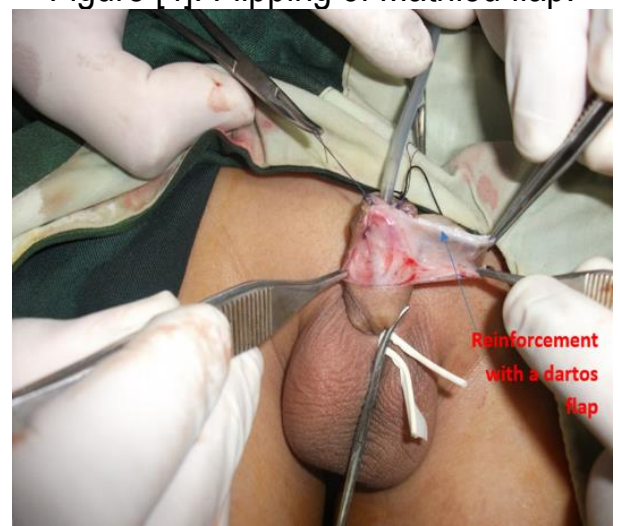

Figure [6]: Reinforcement with a dartos flap. 
Dartos flap is raised from dorsal prepuce followed by ventral chordee bands division. Test penile straightening by artificial erection test. Mark the glans wings before raising on both sides. Midline urethral plate incision is done for widening purpose. A 6 Fr. nelaton catheter is inserted before $6 / 0$ vicryl suturing for urethroplasty. All sutures are inserted in a subcuticular fashion. Mobilize the corpus

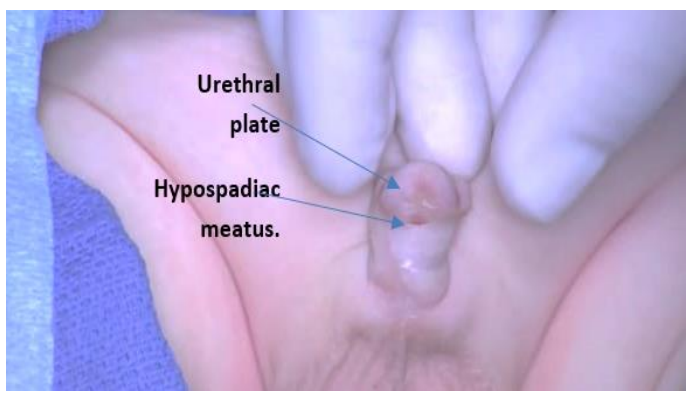

Figure [8]: A case of distal hypospadias

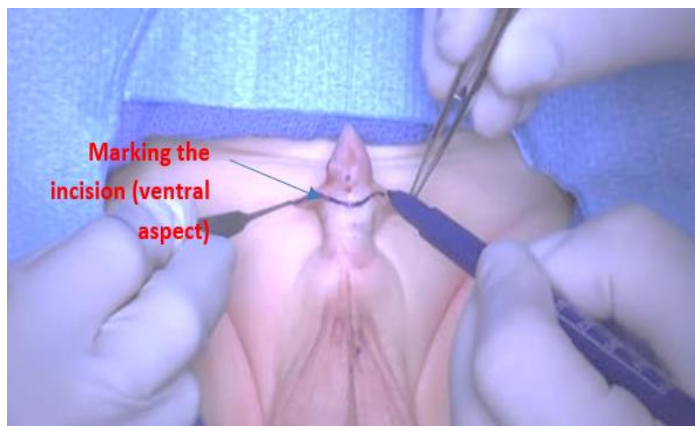

Figure [10]: Pre-operative marking [ventral aspect].

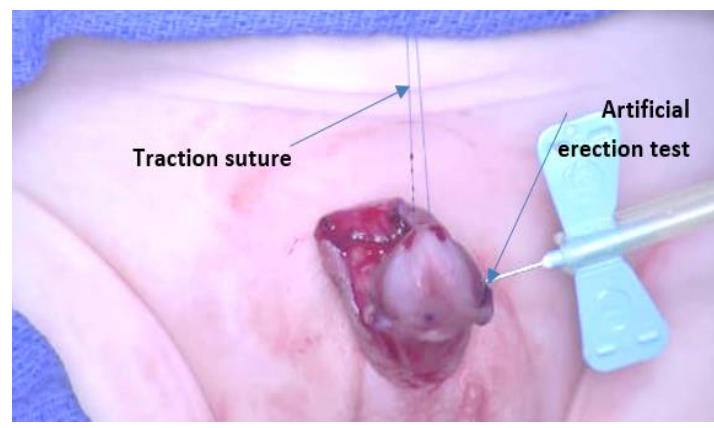

Figure [12]: Artificial erection test

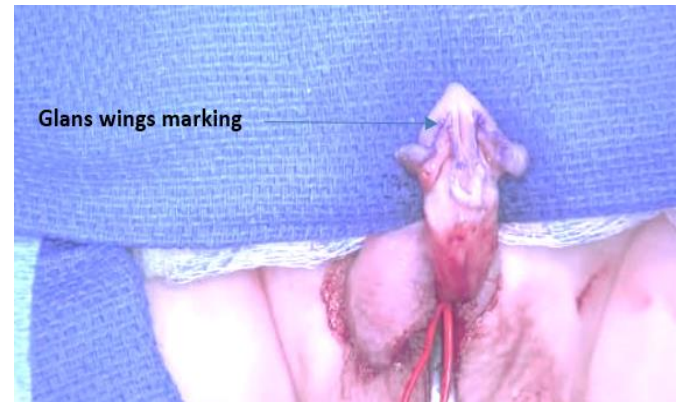

Figure [14]: Glans wings marking spongiosum for spongioplasty acting as a 2nd layer for urethroplasty covering using a 6/0 vicryl. Dartos flap is transposed ventrally as a 3rd layer for extra protection against fistula. Glansplasty is started by ventral mucosal collar approximation, then release the tourniquet and Byars flap are marked on dorsal prepuce and brought ventrally. Last step is trimming excess prepuce followed by ventral skin closure in a cosmetic fashion. Dress the wound with a soft gauze.

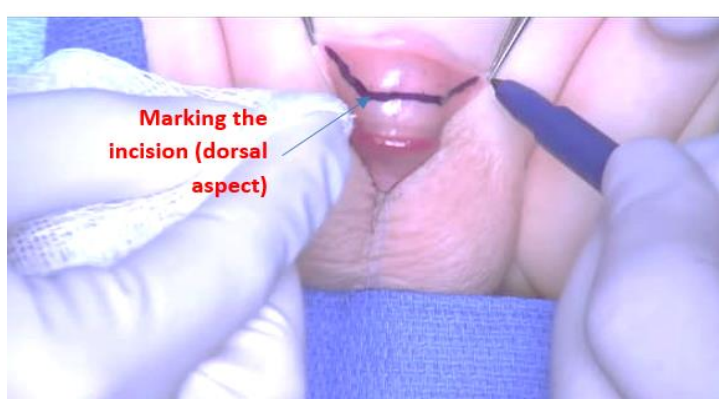

Figure [9]: Pre-operative marking [dorsal aspect].

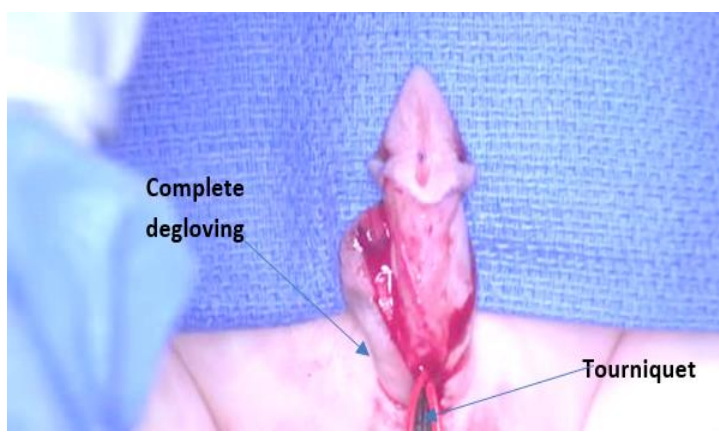

Figure [11]: Penile degloving

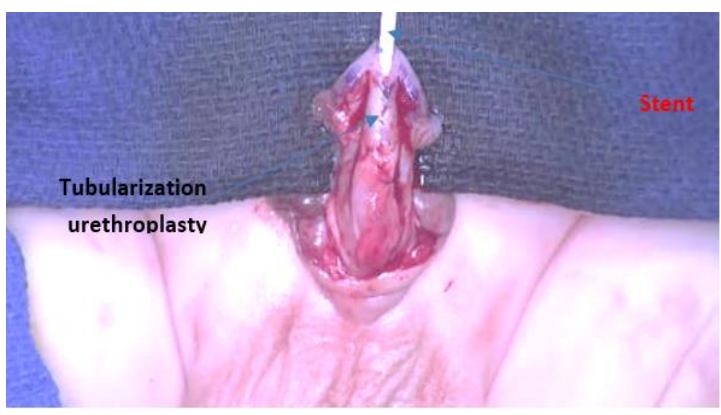

Figure [13]: Tubularization urethroplasty

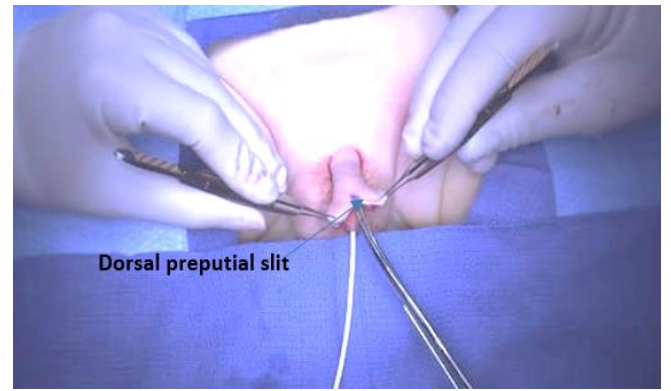

Figure [15]: Dorsal preputial slit 


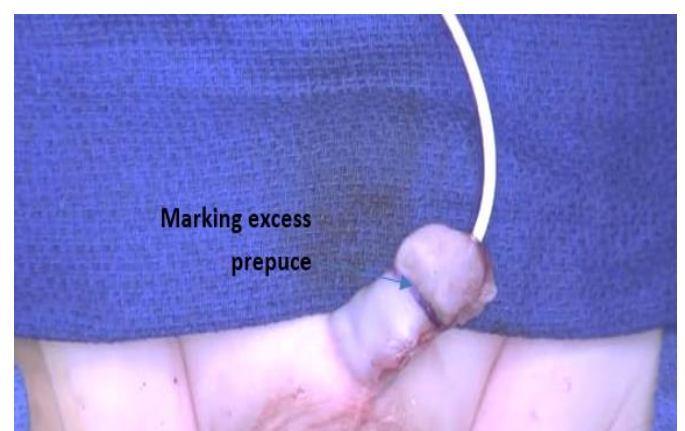

Figure [16]: Making excess prepuce

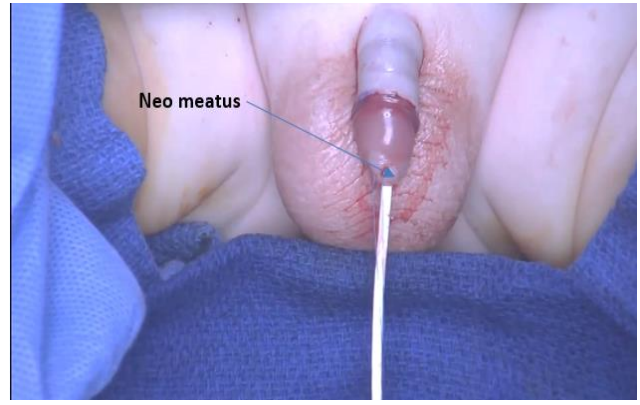

Figure [18]: Neo-meatus

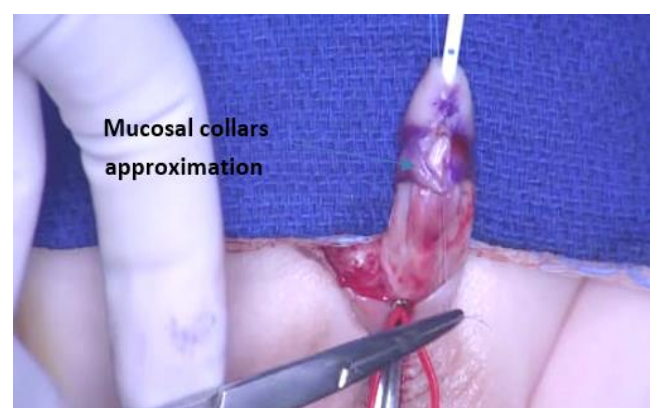

Figure [17]: Mucosal collars approximation

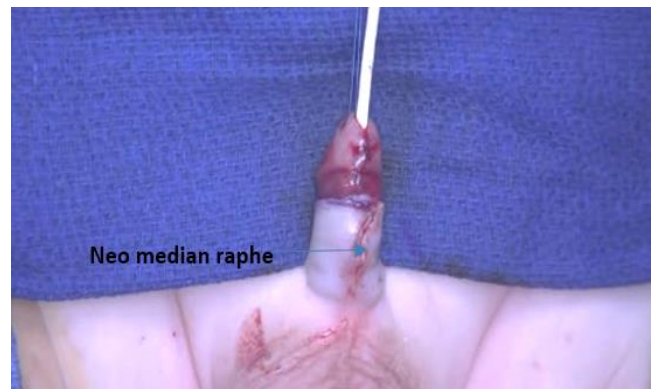

Figure [19]: Neo-median raphe

\section{Post-operative care}

All patients were admitted and followed up in the Department of Surgery, Al-Azhar university hospital with post-operative treatment in the form of broadspectrum antibiotic prophylaxis and analgesia, dressing of the penis for first 5 days after surgery and the wound was laid open. After that, the catheter was removed 7:14 days postoperatively, then patients were discharged home. Patients were investigated in the follow-up visits on a weekly basis for the first month and on monthly basis for the next 12 months. Impression about the cosmetic outcome was made by a surgeon who was unaware about the type of procedure performed [Snodgrass or Mathieu's repair] to minimize the observer's bias. Mean period of follow up was about 8 months. All patients were assessed for current voiding status, cosmesis, complications and any additional procedures required to correct those complications.

Ethical consideration: All selected parents of participants received comprehensive information regarding objectives and the expected benefits of the study. All ethical considerations were taken throughout the whole work. An informed verbal consent from all parents of participants was taken and confidentiality of information was assured. An official written administrative permission letter was obtained from dean of faculty of medicine, Al-Azhar

university hospital in new Damietta manager, Head of the Department of Surgery in the same university. The title and objectives of the study were explained to them to ensure their cooperation. Permission from the faculty of medicine ethical committee was also obtained and approval from institutional review board was taken.

Statistical Analysis: Analysis of data was done using Statistical Program for Social Science version 20 [IBM ®SPSS® Inc., Chicago, IL, USA]. Quantitative variables were described in the form of mean and standard deviation. Qualitative variables were described as number and percent. In order to compare parametric quantitative variables between two groups, Student $t$ test was performed. Qualitative variables were compared using chisquare $\left[\mathrm{X}^{2}\right]$ test or Fisher's exact test when frequencies were below five. Pearson correlation coefficients were used to assess the association between two normally distributed variables. When a variable was not normally distributed, Mann Whitney $[U]$ test for comparing two non-Parametric variables. Kruskal Wallis test for comparing more than two nonParametric variables.

\section{RESULTS}

This study was conducted over 40 male children 
with fresh distal penile hypospadias whose ages range from 1.5-15 years. Group1: included 20 cases managed by Mathieu repair, and Group 2: included 20 cases managed by Snodgrass repair. In the present study, the mean age of the patients at the time of operation was 6.4 years for Mathieu repair group versus 5.9 years for the Snodgrass repair group. There is no significant difference between the studied groups as regard age. In addition, there is no significant difference between the studied groups as regard history of consanguinity and maternal drug intake during gestation.

Results of the present work shoed that, there is no significant difference between the studied groups as regard urethral plate characteristics. $100 \%$ of cases in both techniques had healthy urethral plate. In addition, there is significant difference between the two included techniques as regard operative time, with longer duration in Snodgrass urethroplasty. Also, there was no significant difference between the two techniques as regard length of hospital stay post operatively. Furthermore, there is significant difference between the two studied groups as regard postoperative complications. $20 \%$ of cases in Mathieu group showed urethrocutaneous fistula in comparison to $0 \%$ in Snodgrass group. $10 \%$ of Snodgrass urethroplasty showed meatal stenosis in comparison to $0 \%$ in Mathieu technique [Table 1].

Results of the present study revealed that, there is significant difference between the two studied groups as regard cosmetic appearance of the penis. $100 \%$ of cases in Snodgrass group showed excellent cosmetic outcome in comparison to $40 \%$ only in Mathieu group provided satisfaction regarding cosmesis, in addition to mild torsion of the shaft in $20 \%$ of Mathieu technique candidates. In addition, there is high significant difference between the two studied groups as regard the shape of meatus. 100\% of cases in Snodgrass group showed slit like and vertically oriented meatus and $90 \%$ in Mathieu group showed round and regular appearance [Table 2]

Table [1]: Urethral plate, operative duration, hospital stay duration and complications among studied groups

\begin{tabular}{|c|c|c|c|c|c|}
\hline & & $\begin{array}{l}\text { Group1 } \\
{[n=20]}\end{array}$ & $\begin{array}{l}\text { Group2 } \\
{[n=20]}\end{array}$ & Test & P-value \\
\hline \multirow[t]{2}{*}{ Urethral plate } & Healthy & $20[100.0 \%]$ & $20[100.0 \%]$ & \multirow[t]{2}{*}{0.001} & \multirow[t]{2}{*}{1.0} \\
\hline & Not healthy & $0[0.0 \%]$ & $0[0.0 \%]$ & & \\
\hline Duration of operation & $\begin{array}{l}\text { Mean } \pm \text { SD } \\
\text { Range }\end{array}$ & $\begin{array}{c}60.0 \pm 9.60 \\
40-80\end{array}$ & $\begin{array}{c}80.0 \pm 16.1 \\
45-110\end{array}$ & 4.76 & $<0.001^{*}$ \\
\hline $\begin{array}{l}\text { Length of hospital stay } \\
\text { [days] }\end{array}$ & $\begin{array}{l}\text { Mean } \pm \text { SD } \\
\text { Range } \\
\end{array}$ & $\begin{array}{c}3.0 \pm 0.9 \\
2-5\end{array}$ & $\begin{array}{c}2.5 \pm 0.7 \\
2-4\end{array}$ & 1.9 & 0.07 \\
\hline \multirow[t]{5}{*}{ Complications } & No complications & $14[70.0 \%]$ & $18[90.0 \%]$ & \multirow{5}{*}{8.50} & \multirow{5}{*}{$0.037^{*}$} \\
\hline & Wound breakdown & $2[10.0 \%]$ & $0[0.0 \%]$ & & \\
\hline & Fistula & $4[20.0 \%]$ & $0[0.0 \%]$ & & \\
\hline & Meatal stenosis & $0[0.0 \%]$ & $2[10.0 \%]$ & & \\
\hline & Urethral Stricture & $0[0.0 \%]$ & $0[0.0 \%]$ & & \\
\hline
\end{tabular}

${ }^{*}$ Significant

Table [2]: Comparison between the studied groups as regard penile cosmetic appearance and shape of the meatus

\begin{tabular}{|c|c|c|c|c|c|}
\hline & & $\begin{array}{c}\text { Group } 1 \\
{[n=20]}\end{array}$ & $\begin{array}{c}\text { Group } 2 \\
{[n=20]}\end{array}$ & Test & P-value \\
\hline \multirow{3}{*}{$\begin{array}{c}\text { Cosmetic appearance } \\
\text { of the penis }\end{array}$} & Excellent & $8[40.0 \%]$ & $20[100.0 \%]$ & \multirow{3}{*}{17.14} & \multirow{3}{*}{$<0.001^{*}$} \\
\hline & Good & $8[40.0 \%]$ & $0[0.0 \%]$ & & \\
\hline & Mild torsion of the shaft & $4[20.0 \%]$ & $0[0.0 \%]$ & & \\
\hline \multirow[t]{2}{*}{ The shape of the meatus } & Slit like and vertically oriented & $2[10.0 \%]$ & $20[100.0 \%]$ & \multirow{2}{*}{32.72} & \multirow{2}{*}{$<0.001^{*}$} \\
\hline & Round and regular & $18[90.0 \%]$ & $0[0.0 \%]$ & & \\
\hline
\end{tabular}

\section{DISUCSSION}

The main objectives of this study were to compare between the meatal-based flap "Mathieu" technique and Tubularized Incised Plate [TIP] "Snodgrass" urethroplasty in treatment of distal hypospadias. There was no significant difference between both groups regarding patient age or sex.
These results are supported by study of Maitra et al.[17]. They reported that, the mean age of patient in Snodgrass repair was 3.5 years vs 3.7 years in Mathieu repair, the difference being statistically insignificant. In addition, Hamid et al.[18] observed that, there was no significant difference between both groups, $6.4 \pm 3.3$ in group $A$, and $5.9 \pm 3.1$ years in group $B$. 
In contrary of our results, Badr et al.[19] reported that there was significant difference between the studied groups as regard age. This could be due to different inclusion criteria.

The present study shows that there is no significant difference between the studied groups as regard history of consanguinity, maternal drug intake during gestation, and urethral plate characteristics. Our results are in agreement with study of Tawfiq et al.[20] as they reported that Mathieu repair was performed in 24 [48\%] patients and tubularized incised plate [TIP] urethroplasty [Snodgrass procedure] in the rest of 26 [52\%] patients. Urethral plate was healthy in all patients. El-Mageed et al.[21] reported that Six cases [15\%] had positive family history.

Hypospadias is recognized as a common congenital malformation of the urethra and phallus, which requires a safe and proper surgical treatment to avoid additional comorbidities and psychological complications in the affected children. Mathieu perimeatal based flip-flap technique [1932] and Snodgrass method of TIP [tubularized incised plate] procedure [1994] are the two most widely practiced methods which uses native urethral plate in the repair process ${ }^{[22]}$.

The current study shows that, there is significant difference between the two included techniques as regard duration of surgery, with longer duration in Snodgrass approach. Our results are supported by study of Tawfiq et al.[20] as they revealed a statistically significant difference of the total time of operation between the two surgical techniques .Operative time ranged from 45 to 75 minutes [Mean $=60 \pm 6.7$ minutes] for Mathieu group and 75 to 105 minutes [Mean=90 \pm 7.1 minutes]. Hamid et al. [18], reported that, the mean operative time in group $A$ [TIP repair] was $63.7 \pm 14.4$ [45-90] and group $-B$ [Mathieu's repair] was $95.0 \pm 19.1$ [70-125] minutes, with significant difference $[P<0.05]$. In addition, Maitra et al. [17], reported that, mean operative time for Snodgrass and Mathieu procedure were 63 minutes [range 47-90 minute] and 57 minutes [range 41-75 minute] respectively. There was significant difference between groups. Furthermore, Badr et al.[19], found that the mean operative time was shorter in Snodgrass procedure versus MMP [70 versus 100 minutes respectively]. This was also seen in reports of Moradi et al.[22], who reported shorter operative time in Snodgrass procedure favors this technique, as it exposes the patients to lesser anesthetic time and potential iatrogenic complications.

In contrary of our results, Guo et al. [23] reported that, the mean operative time was markedly reduced in Snodgrass than Mathieu repair.

Complications are usually common after hypospadias correction surgery, extending from fistulae to complete damage of the neourethra with need for total reconstruction. Fistulae usually developed with hypospadias reconstruction irrespective of surgeon's experience. The meatalbased flap urethroplasty is commonly indicated for the primary correction of distal hypospadias. However, the two suture lines necessary for the flap increase the risk of developing a coronal urethrocutaneous fistula. There is also an increased risk of meatal stenosis because the blood flow in the distal part of the flap is reduced[17].

In the current study, there was no significant difference between the two techniques as regard length of hospital stay. There was significant difference between the two studied groups as regard complication. Our results are supported by study of Badr et al. ${ }^{[19]}$ as they reported that, complication rate in Snodgrass was $15 \%$ in the form of urethrocutaneous fistula in two patients and one patient with meatal stenosis, whereas in modified Mathieu repair, it was $10 \%$ in the form of one patient with urethrocutaneous fistula and one patient with meatal stenosis.

Saleem et al.[24] reported that complication rate differences between the two groups were not statistically significant: $15 \%$ for Snodgrass versus $10 \%$ for MP. It was found that urethrocutaneous fistula and meatal stenosis are the most common complications reported, and they are like those reported by Maitra et al.[17], who reported that, complications were found in 6 patients each in Snodgrass [18\%] in comparison with Mathieu Procedure [22\%].In Snodgrass procedure 2 had urethrocutaneous fistula [6\%] and 2 had meatal stenosis [6\%] in comparison with 3 fistula [11\%] and 2 cases of meatal stenosis [7.4\%] in Mathieu repair. In the series of Hamid et al. ${ }^{[18]}$, complications were seen in 28 [28.0\%] patients. The complications included wound infection [5.76\%] and [8.3\%] in groups $A$ and $B$ respectively. Currently, there is 
anticipated rate complications between [5-10\%]; mainly fistulas in one-stage urethroplasty. The fistula and meatal stenosis rate was more common in Mathieu's group. It could be explained by the necessity for two suture lines in case of Onlay flap maneuver on each side which might be threatening the vascular supply of the flap.

Cheng et al.[25] have advocated a two-layer closure of the neourethra to decrease the fistula rate. Meatal stenosis is mostly occurred as a result of technical fault; not confining the dorsal midline incision to the urethral plate. Other comorbidities such as urethral stricture, diverticulum, and wound breakdown are infrequent. Rabinowitz [26] has reported the complication rate of $13.5 \%$ in stent less Mathieu repair. Hakim et al..[27] compared the results of the Mathieu procedure with and without a catheter and reported complication rate of $2.7 \%$ in stented and $3.6 \%$ in unstented repair. However, Buson et al.[28] noted a significantly higher complication rate of $18.9 \%$ in stentless versus $4.6 \%$ in stented cases. Tawfiq et al. [20] reported that, there is a significantly high rate of fistula formation with Mathieu repair than in Snodgrass repair [7.7\% versus 3.3\%]. Other complications included breakdown of the wound and meatal stenosis are equally occur after both techniques. Stricture formation is slightly more common in Mathieu repair [3.3\% versus 2.2\%]. These results agree with previous studies. In one study of Imamuglu et al.[29] wound breakdown and flap necrosis have been reported more frequently with Snodgrass technique with no significant difference between both maneuvers regarding fistula and total success rate. El-Mageed et al. [21], reported that, urethrocutaneous fistula was noted in 4 cases [20\%] of the Mathieu group including 2 of them were associated with meatal stenosis and were successfully repaired later. This is compared with 3 cases of the Snodgrass group two cases of them were associated with stenosis and closed spontaneously while one case was successfully repaired later. Post-operative edema was noticed in 6 patients [30\%] in Mathieu group compared to 2 cases $[10 \%]$ in Snodgrass group. All cases improved few days later. Urine retention was noticed in two patients [one of each group] and relieved by $8 \mathrm{Fr}$. catheter [the catheter was left for ten minutes].

The present study shows that there is significant difference between the two studied groups as regard cosmetic appearance of the penis $100 \%$ of cases in Snodgrass group showed Excellent in comparison to $40 \%$ in Mathieu group, $20 \%$ in Mathieu group showed Mild torsion of the shaft. These results are supported by study of Imamuglu et al.[29] as they reported that excellent cosmetic results have been reported with $0.5 \%$ meatal stenosis, $1 \%$ urocutaneous fistula and rate of reoperation $1.5 \%$. In series of Tawfiq et al.[20], excellent cosmetic was achieved in 24 [92.31\%] patients in the Group A and in the Group B cosmetic appearance was excellent in 10 [41.67\%] patients and 8 [16.7\%] patients had mild torsion of shaft. Their cosmetic outcome after Snodgrass repair urethroplasty was similar to that reported by authors like Anwar-Ul-Haq et al.[30] and Guo et al.[23].

Regarding Maitra et al. [17], cosmesis was excellent in $90 \%$ of cases in Snodgrass repair compared to $82 \%$ in Mathieu repair. There was mild torsion in $18 \%$ cases with Mathieu repair compared to none in Snodgrass procedure. El-Mageed et al.[21] reported that, there was no penile torsion in the Mathieu group. One case of less than thirty-degree torsion occurred in the Snodgrass group and necessitated no further intervention.

Hinging the plate facilitates glans folding during glanuloplasty, extending the meatus to the tip of the penis, offers substantial mobilization of urethral plate for tubularization with or without additional skin flaps, and helps generate a cosmetically normal, centrally located, vertically oriented urethral meatus ${ }^{[21]}$.

The current study shows that there is high significant difference between the two studied groups as regard the shape of meatus $100 \%$ of cases in Snodgrass group showed slit like and vertically oriented and $90 \%$ in Mathieu group showed round and regular. Our results are supported by study of Moradi et al. [22] as they reported that regarding shape, the meatal opening configuration was superior in Snodgrass [vertical or oval] than MMP [rounded], and this raises the question of which is the best technique for the patient. Maitra et al..[17] found that meatal orientation was vertical slit like in $>90 \%$ of cases of Snodgrass repair whereas it was rounded in $>90 \%$ of Mathieu repair cases. Hamid et al.[18] observed that cosmesis of penis is of concern to the parents. This cosmesis was best accomplished with TIP urethroplasty rather than Mathieu's repair. TIP generates a vertically oriented, 
slit-like meatus with normal look which is desired from the cosmetic point of view. Tawfiq et al.[20], reported that, cosmesis of penis is concerned by the parents and best attained by Snodgrass repair. Snodgrass repair creates a vertically oriented, slit like normal looking meatus which is cosmetically desirable.

In short, Snodgrass and modified Mathieu repair were safe, and the choice of one of the techniques will depend on the surgeon's decision.

\section{Financial and Non-Financial Relationships and Activities of Interest}

None declared by the author

\section{REFERENCES}

1. Andersson KE. Autonomic Regulation of Penile Erection. In Oxford Research Encyclopedia of Neuroscience. Published online May 2019; available at: https://oxfordre.com/neuroscience/view/10.1093/acrefor e/9780190264086.001.0001/acrefore-9780190264 086 e-272?rskey=1Cwyg1\&result=9 [DOI:10.1093/ acrefore/ 9780190264086.013.272].

2. Gomez RG, Campos RA, Velarde LG. Reconstruction of pelvic fracture urethral injuries with sparing of the bulbar arteries. Urology 2016; 88: 207-212. [DOI: 10.1016/j.urology.2015.09.032].

3. Henry BM, Pękala PA, Vikse J, Sanna B, Skinningsrud B, Saganiak K, Tomaszewski KA. Variations in the arterial blood supply to the penis and the accessory pudendal artery: a meta-analysis and review of implications in radical prostatectomy. J Urol. 2017; 198[2]: 345-353. [DOI: 10.1016/j.juro.2017.01.080].

4. Levin RJ. Anatomy and Physiology in the Male. ABC of sexual health. Oxford: Wiley 2015, pp 7-11.

5. Fusco F, Creta M, Mirone V. Penis: Ultrasound Anatomy and Scanning Methods. In Atlas of Ultrasonography in Urology, Andrology, and Nephrology. Springer, Cham 2017, pp. 543-550.

6. Lohasammakul S, Turbpaiboon C, Ratanalekha R, Ungprasert P, Yodrabum N. Inferior external pudendal artery anastomosis: Additional approach to prevent skin necrosis in replanted penis. Plast Reconstr Surg. 2018; 142[4]: 535e-540e. [DOI: 10.1097/PRS. 000000000000 4818].

7. Sam P, LaGrange C. Anatomy, Abdomen and Pelvis, Penis. StatPearls. 2020. Treasure Island [FL]: StatPearls Publishing; 2020. [PMID: 29489230].

8. Warburton NM, Bateman PW, Fleming PA. [2019]. Anatomy of the cavernous muscles of the kangaroo penis highlights marsupial-placental dichotomy. J Anat. 2019; 234 [3]: 306-315. [DOI: 10.1111/joa.12930].

9. Mahadevan V. Anatomy of the lower urinary tract. Surgery [Oxford] 2016; 34 [7]: 318-325. [DOI: 10.1016/ j.mpsur.2016.04.001].

10. Kadono $\mathrm{Y}$, Machioka $\mathrm{K}$, Nakashima K, lijima $M$, Shigehara K, Nohara T, et al. Changes in penile length after radical prostatectomy: investigation of the underlying anatomical mechanism. BJU int. 2017; 120[2]: 293-299. [DOI: 10.1111/bju. 13777]

11. Ntoulia A, Papadopoulou F, Benz-Bohm G. Urinary Tract Embryology, Anatomy, and Anatomical Variants. In Pediatric Urogenital Radiology, 2018; Springer, Cham. pp. $135-150$

12. Tiftikcioglu YO, Erenoglu CM, Lineaweaver WC, Bilge O, Celik S, Ozek C. Anatomic basis for penis transplantation: cadaveric microdissection of penile structures. Ann Plast Surg 2016; 76[6]: 729-734. [DOI: 10.1097/SAP.0000000000000825]

13. Campos-Juanatey F, Bugeja S, Ivaz SL, Frost A, Andrich DE, Mundy AR. Management of penile urethral strictures: Challenges and future directions. World J Clin Urol. 2016; 5[1]:1-10. [Doi: 10.5410/wjcu. v5.i1.1].

14. Rais-Bahrami, S., Richards, G., \& Gilbert, B. R. [2017]. Penile ultrasound. In Practical Urological Ultrasound. Humana Press, Cham. pp. 129-156

15. Cozzi D, Verrone GB, Agostini S, Bartolini M, D'Amico G, Pradella S, Miele V. Acute penile trauma: imaging features in the emergency setting. Radiol Med 2019 Dec; 124 [12]:1270-1280. [DOI: 10.1007/s11547-019-010651].

16. Benz KS, Dunn E, Maruf M, Facciola J, Jayman J, Kasprenski M, et al. Novel anatomical observations of the prostate, prostatic vasculature and penile vasculature in classic bladder exstrophy using magnetic resonance imaging. J Urol. 2018; 200[6]: 1354-1361. [DOI: 10.1016/j.juro.2018.06.020].

17. Maitra SG, Kumar R, Das SK. Distal penile hypospadias repair with Snodgrass and Mathieu procedure: A comparative study. [IOSR-JDMS 2019; 18 [6]: 41-42. [DOI: 10.9790/0853-1806014142].

18. Hamid R, Baba AA, Shera AH. Comparative Study of Snodgrass and Mathieu's Procedure for Primary Hypospadias Repair. ISRN Urol. 2014 Apr 27; 2014: 249765. [DOI: 10.1155/2014/249765].

19. Badr ML, Loulah MA, Eltatawy AG, Gamea AS. A comparative study between Snodgrass versus Mathieu with dartos flap urethroplasty for distal hypospadias repair. Menoufia Med J. 2019; 32[2]: 489. [DOI: 10.4103/mmj.mmj_578_17].

20. Tawfiq NR, Saood MJ, Abdulla MH. Comparative study of two different procedures for primary hypospadias repair. Int Surg J. 2017; 4[8]: 2475-2479. [DOI: 10.18203/2349-2902.isj20173162].

21. El-Mageed MA, Husein A, El-Moez W. Randomized comparative study between Mathieu flip-flap and snodgrass techniques for the repair of distal hypospadias. Egypt J Plast Reconstr Surg. 2007; 31: 157-65.

22. Moradi M, Moradi A, Ghaderpanah F. Comparison of Snodgrass and Mathieu surgical techniques in anterior distal shaft hypospadias repair. Urol J. 2005; 2:28-31. [PMID: 17629892].

23. Guo $Y, M a G, G e Z$. [Comparison of the Mathieu and the Snodgrass urethroplasty in distal hypospadias repair]. Zhonghua Nan Ke Xue [National J Androl]. 2004; 10[12]: 
916-918. [PMID: 15638022] , Article in Chinese [English Abstract].

24. Saleem MS, Rasool M, Pansota MS, Tabassum SA. Comparative study between tubularized incised plate uretroplasty [Snodgrass] and reverse flap [Mathieu] repair in distal hypospadias. Ann Pak Inst Med Sci. 2012; 8:96-100.

25. Cheng EY, Vemulapalli SN, Kropp BP. Snodgrass hypospadias repair with vascularised dartos flap: The perfect repair for virgin cases of hypospadias? J Urol. 2002:168:1723-6. [ DOI: 10.1097/01.ju. 0000026940. 33540.31].

26. Rabinowitz $\mathbf{R}$ Outpatient catheterless modified Mathieu hypospadias repair. J Urol. 1987; 138:1074- 82. [DOI: 10.1016/s0022-5347[17]43506-3].
27. Hakim S, Merguerian PA, Rabinowitz R., Shortliffe LD, McKenna PH. Outcome analysis of the modified Mathieu hypospadias repair: comparison of stented and unstented repairs. J Urol. 1996; 156:836-43. [DOl: 10.1097/ 00005392-199608001-00081].

28. Buson H, Smiley D, Reinberg Y, Gonzalez R. Distal hypospadias repair without stents: is it better? J Urol.1994; 151:1059-64. [DOI: 10.1016/s0022-5347 [17]35180-7].

29. Imamuglu MA, Bakirta H. Comparison of two methodsMathieu and Snodgrass- in hypospadias repair. Urollnt. 2003; 71:251-4. [DOl: 10.1159/000072674].

30. Anwar-UI-Haq AU, Akhter N, Nilofer N, Samiullah S, Javeria J. Comparative study of Mathieu and Snodgrass repair for anterior hypospadias. J Ayub Med Col Abbottabad. 2006;18[2]:50-2. [PMID: 16977814]. 